\title{
JOURNAL.RU
}

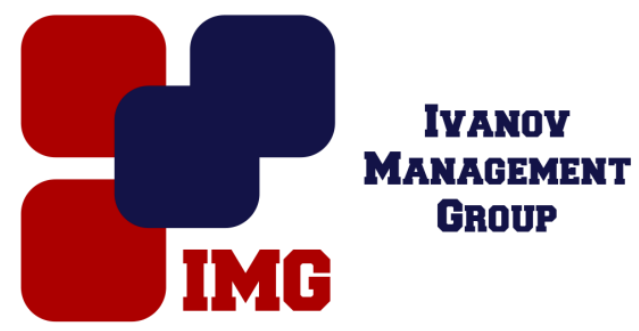

Скорляков В.В., Бабиев В.Ф., Кещян С.С. ФГБОУ ВО «Ростовский государственный медицинский университет»

Минздрава России Ростов-на-Дону, Россия

doi: 10.18411/1j-31-05-2017-41

idsp 000001:1j-31-05-2017-41

\section{Синдром диссеминированного внутрисосудистого свёртывания в хирургической практике}

Синдром диссеминированного внутрисосудистого свёртывания (ДВС) типовой патологический процесс, характеризующийся генерализованной активацией систем гемостаза и фибринолиза и рассогласованием систем регуляции агрегантного состояния крови [1]. С проявлениями этого синдрома могут встретиться врачи всех специальностей. ДВС - синдром требует своевременной диагностики и незамедлительно начатого адекватного лечения.

Современные представления о ДВС - синдроме можно сформулировать следующим образом [2]:

1. ДВС - синдром всегда вторичен, он развивается под действием различных индукторов.

2. В развитии ДВС - синдрома отмечается «дозовая зависимость», то есть, чем активнее заболевание - индуктор, тем острее ДВС синдром.

3. ДВС - синдром всегда сопровождается полиорганной недостаточностью.

4. ДВС - синдром лишен стадийности течения, однако по клиниколабораторным показателям выделяют молниеносный, острый и хронический ДВС - синдром.

В качестве индукторов ДВС - синдрома могут выступать патологические состояния, вызывающие активацию как внешнего, так и внутреннего пути свертывания крови. 
К первой группе индукторов ДВС - синдрома относятся различные виды шока [3, 4], хирургические вмешательства на паренхиматозных органах, острый панкреатит, тяжелые стафилококковые инфекции $[5,6,7,8]$, , массивная кровопотеря $[9,10]$, большие дозы бактерицидных антибиотиков $[11,12,13]$, краш - синдром, внутрисосудистый гемолиз, массивная гемотрансфузия и реинфузия крови $[14,15]$, злокачественные опухоли, лейкозы и другие.

Активация коагуляционного гемостаза по внутреннему пути свертывания развивается вследствие повреждения эндотелия сосудистой стенки при генерализованных инфекциях, геморрагических васкулитах, хронической почечной недостаточности, аутоиммунных заболеваниях, при наличии эндопротезов и шунтов, которые требуют постоянной антикоагулянтной терапии $[16,17]$.

Частыми причинами развития данного синдрома являются ятрогенные воздействия: лечение препаратами, вызывающими агрегацию тромбоцитов, повышающими свертываемость крови, препаратами дефибринирующего действия, препаратами, снижающими противосвёртывающий и фибринолитический потенциал крови $[18,19]$, а также длительная искусственная вентиляция легких.

Вероятность развития острого ДВС - синдрома может быть заподозрена при наличии следующих клинических признаков:

- острая недостаточность (дыхательная, печеночная, почечная или др.);

- множественные геморрагии разной локализации;

- сочетание тромбоза (инфаркта) с кровоточивостью;

- шок затяжной с геморрагиями;

- комбинированная недостаточность двух и более органов (например, лёгочная и почечная); выраженная локальная кровоточивость.

Для диагностики ДВС-синдрома не существует одного чувствительного лабораторного теста. Диагностика должна быть комплексной, с использованием ряда лабораторных методов, которые оцениваются с учётом клинической картины.

Основной скрининговый набор тестов, который позволяет поставить диагноз ДВС - синдрома, включает подсчет количества тромбоцитов, определение времени кровотечения, фибриногена, продуктов деградации 
фибрина (ПДФ), растворимых фибрин - мономерных комплексов (РФМК), тромбинового и активированного тромбинового времени (ТВ и АПТВ).

При выявлении тромбоцитопении (то есть, при снижении количества тромбоцитов ниже 160 х 109/л) необходимо, прежде всего, исключить ДВС синдром. С этой целью следует оценить уровень РФМК в крови (он не должен превышать лабораторную норму).

При выявлении удлинения времени кровотечения (в норме 2-3 минуты) на фоне нормального уровня тромбоцитов можно предполагать тромбоцитопатию или болезнь Виллебранда. Для исключения последнего необходим тщательный сбор анамнеза (наличие частых эпизодов кровоточивости, отягощенная наследственность, прием медикаментов). При отсутствии данных в пользу болезни Виллебранда показано исследование агрегационной и адгезивной функций тромбоцитов. При этом так же необходимо исключить ДВС - синдром.

При снижении уровня фибриногена в крови необходимо исключить наследственную афибриногенемию (наследственный анамнез) и ДВС - синдром (определить уровень РФМК).

При выявлении повышенного уровня в крови РФМК делают однозначный вывод о наличии у пациента ДВС - синдрома [20]. Если фибриноген при этом в крови низкий, то речь идет об остром ДВС-синдроме, а если уровень фибриногена соответствует норме или превышает ее - то это хронический ДВСсиндром [21 - 24]. В этом случае проводится лечение ДВС- синдрома в полном объеме.

Эта первичная информация дополняется затем более точными стандартизованными методами :

- исследованием динамики тромбоцитов, их числа и внутрисосудистой активации; фрагментации эритроцитов и их числа в мазке крови;

- исследованием адгезивно-агрегационных свойств тромбоцитов;

- определением активированного парциального тромбопластинового времени (АПТВ), свободного гепарина, уровня АТІІІ и др.;

- определением времени эуглобулинового лизиса, индекса резерва плазминогена, XII-A зависимого фибринолиза, фрагментов 1,2, антифосфолипидных антител (АФА), протамина С (ПрС), Dдимеров. 
При наличии соответствующей клинической ситуации и симптомов ДВС, выявление совокупности хотя бы 4 - 5 из основных и дополнительных лабораторных признаков должно рассматриваться как подтверждение диагноза и служить основанием для проведения необходимой патогенетической терапии.

1. Крашутский В.В. ДВС - синдром в клинической медицине. Клин. мед. 1998. № 3. С. 8-14.

2. Руководство по гематологии. Том 3. Под ред. А.И. Воробьева.- М.: «Ньюдиамед», 2005. $-411 \mathrm{c}$.

3. Скорляков В.В., Дударев И.В., Кещян С.С., Подина М.В. Лечение больных с острыми язвенными гастродуоденальными кровотечениями. В сб: Актуальные проблемы медицины в России и за рубежом. Сборник науч тр по итогам междунар науч-практ конф. 2015. С. 171-174.

4. Кещян С.С. Комплексное лечение острых язвенных гастродуоденальных кровотечений в зависимости от архитектоники сосудистого русла в зоне локализации язвы. Автореф. на соиск...канд. мед наук. Ставрополь, 2012.

5. Бабиев В.Ф. Прогнозирование и контроль течения острых хирургических заболеваний, осложненных перитонитом. Автореф. на соиск...канд. мед наук. Ростовна-Дону, 1996.

6. Стагниева И.В., Симбирцев А.С. Значение цитокинового профиля в проявлении болевого симптома при риносинусите // Цитокины и воспаление. 2015. Т. 14. № 4. С. 29-34.

7. Стагниева И.В. Роль субстанции Р в патогенезе лицевой боли при риносинусите // Российская ринология. 2015. Т.23. № 1. С. 33-35.

8. Стагниева И.В., Симбирцев А.С. Роль цитокинов в патогенезе лицевой боли при риносинусите // Медицинская иммунология. 2015. Т. 17. № S. С. 319.

9. Чернов В.Н., Скорляков В.В., Маслов А.И. Диагностика и лечение больных с язвенными гастродуоденальными кровотечениями. Вестник эксперим. и клин. хирургии. 2014. № 1. С. 82.

10. Скорляков В.В., Маслов А.И., Бароков Э.М. Тактика лечения больных с острыми гастродуоденальными язвенными кровотечениями. Вестник эксперим. и клин. хирургии. 2010. Т.3 № 1. С. 52-55.

11. Стагниева И.В., Гукасян Е.Л. Определение степени тяжести риносинусита по цитокиновому балансу //Российский аллергологический журнал. 2016. № 3. С. 83-84.

12. Стагниева И.В. Иммунотропная терапия в лечении рецидивирующего риносинусита // В мире научных открытий. 2017. Т. 9. № 1. С. 56-65.

13. Стагниева И.В. Вегетативная дисфункция в проявлении прозопалгий у больных с риносинуситами // Медицинский вестник Юга России. 2012. № 2. С. 67-69.

14. Чернов В.Н., Скорляков В.В., Кещян С.С. Терапия и хирургия осложненных форм язвенной болезни. Рос. журнал гастроэнтер., гепатол., колопроктол. 2010. Т. 20 № 5. С. 40 . 
15. Чернов В.Н., Скорляков В.В., Баев О.В. Лечение перфоративной язвы гастродуоденальной зоны. Вестник хирургической гастроэнтерологии. 2006. № 1. С. 79.

16. Бойко Н.В., Панченко С.Н. Локализованное внутрисосудистое свертывание крови у больных с носовыми кровотечениями. Новости оториноларингологии и логопат. 2001. № 3. C. 5.

17. Бойко Н.В. Носовые кровотечения как осложнение антитромботической терапии. Российская ринология. 2011. Т. 19. № 4. С. 29-32.

18. Бойко Н.В., Колмакова Т.С., Быкова В.В. Биохимические показатели компенсации постгеморрагической анемии у больных с носовыми кровотечениями. Вестник оторинолар. 2010. № 4. С. 13-16.

19. Бойко Н.В., Колмакова Т.С. Исследование биогенных аминов у больных с носовыми кровотечениями на фоне вегетативной дисфункции . Folia Otorhinolar. et Pathol Res. 2015. T 21. № 2. C. 27-29.

20. Васильев С.А., Воробьев А.И., Городецкий В.М. Протокол диагностики и лечения острого ДВС-синдрома. Проблемы гематологии и переливания крови. 1999. № 3. С. 40 43.

21. Стагниева И.В., Гукасян Е.Л., Сагакянц А.Б. Нарушение нейроиммунной реактивности у больных риносинуситом. Российская ринология. 2015. Т. 23. № 1. С. 25-28.

22. Бойко Н.В., Шатохин Ю.В., Быкова В.В. Патогенетическое лечение рецидивирующих носовых кровотечений на фоне гипертонической болезни. Рос. ринология 2007. № 2. С. 58.

23. Бойко Н.В., Шатохин Ю.В. Патогенез носовых кровотечений у больных с артериальной гипертензией. Вестник оторинолар. 2015. Т. 80. № 5. С. 41-45.

24. Быкова В.В., Залесский А.Ю. Редкая причина рецидивирующего носового кровотечения. Российская ринология. 2015. Т. 23. № 1. С. 52-54. 